\title{
Biomonitoring of airborne micro- particles released by aluminum industry by using naturally occuring radionuclides
}

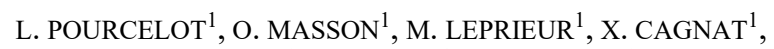
B. BOULET ${ }^{1}$, Y. NOACK ${ }^{2}$, J-C RAYNAL ${ }^{3}$

${ }^{1}$ IRSN Cadarache, bat. 153, 13115 St-Paul-lez-Durance, France

${ }^{2}$ Aix-Marseille Université, CNRS, IRD, INRAE, Collège de France, CEREGE, Aix-en-Provence, France

${ }^{3}$ Aix-Marseille Université, CNRS, ECCOREV, Aix-en-

Provence, France

Industry remains an important source of environmental contamination by heavy metals and metalloids which may pose a serious threat to the ecosystems and the population. The alumina production from bauxite ore gives rise to large amount of liquid and solid wastes since the production of 1 $\mathrm{kg}$ of alumina involves same weight of solid residue, the well-known red muds enriched in iron and heavy metals. Up to now, without any valorization of by-products, the red muds are stored in artificial ponds which are a potential source of pollutants for the surroundings due to the uplift of red dust under strong wind conditions. The development of a biomonitoring study allows filling the gap of knowledge concerning air quality over a wide potentially contaminated area. Thus the current work aims to compare the activity concentration of natural radionuclides $\left({ }^{238} \mathrm{U}\right.$, decay products and ${ }^{232} \mathrm{Th}$ ) in plants leaves (quercus robur and lettuces) and in grains (wheat) with those of aerosols and the potential sources of atmospheric particles from soils and above all the red dust emitted from the dried ponds and from the piles of bauxite. The activity concentration of natural radionuclides such as ${ }^{238} \mathrm{U}$, some decay products and ${ }^{232} \mathrm{Th}$ was determined in plants samples taken according to the two dominant wind directions, at plots located 100 to $1,500 \mathrm{~m}$ from the basins. Furthermore the atmospheric particles were taken in the same areas, using a high volume aerosol sampler. The increase of ${ }^{232} \mathrm{Th}$ and ${ }^{238} \mathrm{U}$ activity concentration in a few trees leaves (a factor 9 and 4, respectively) and in some aerosols samples is accompanied by a decrease of ${ }^{238} \mathrm{U} /{ }^{232} \mathrm{Th}$ activity ratio of these matrices. Such low ratio suggests that the airborne particles emitted by bauxite piles and red mud basins - those latter's are also characterized by low ${ }^{238} \mathrm{U} /{ }^{232} \mathrm{Th}$ - first contaminate the atmosphere and then the leaves surface, after deposition. Available at distance greater than $1,000 \mathrm{~m}$ from the ponds, locally produced foodstuffs do not show any excess of radionuclides, suggesting low influence of airborne micro particles from the alumina production. 